\title{
Teaching Human Development to Early Childhood Education Students: A Cultural-Contextual Perspective
}

\author{
Judith K. Bernhard
}

Ryerson University

Howard A. Smith

Queen's University

digital.library.ryerson.ca/object/18

Please Cite:

Bernhard, J. K., \& Smith, H. A. (1997). Teaching human development to early childhood education students: A cultural contextual perspective. Canadian Journal of Research in Early Childhood Education, 6(1), 7-19.

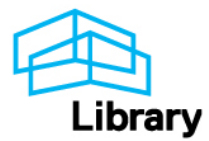




\title{
Teaching Human Development to Early Childhood Education Students: A Cultural-Contextual Perspective
}

\author{
Judith K. Bernhard \\ Ryerson Polytechnic University \\ Howard A. Smith \\ Queen's University
}

\begin{abstract}
The focus of a cultural-contextual approach to development is to recognize the fact that considerable differences exist among human individuals, especially in terms of their diverse sociocultural backgrounds. This paper examines how a group of early clildhood education students responded to the presentation of a cultural-contextual approach during a human dcvelopment course. A variety of data were gathered on the reactions of 81 students enrolled in the course during their first year of a four-year undergraduate degree program in early childhood education. The data reflected a number of course-rclated issues, and the investigation looked for signs that the cultural approach was salient for the students. There appeared to be evidence for only a small degree of success in conveying the approach in terms of students actually mentioning such issues. In analyzing the findings we propose that to reach a larger number of students, it may be necessary to address in a deliberate way the explicit and implicit messages concerning what is important to know about human development. The underlying assumptions of the wider course of study may need to be addressed as well, both at the program level and within the individual courses themselves. Implications for teaching are presented.
\end{abstract}

\begin{abstract}
Résumé
Le point focal d une approche culturelle-contextuelle au développement est de reconnaître le fait qu'il existe des différences considérables parmi les individus humains surtout au niveau de leurs antécédents socioculturels divers. Cet article examine comment un groupe d'étudiants a réagi à la présentation d'une approche culturelle-contextuelle pendant un cours de développement humain. Des données sur les réactions des 81 élèves, dans leur première année d'un programme de quatre ans dans l'étude de la petite enfance, ont été recueillies. Ces donnćes reflètent un nombre de sujets abordés pendant le cours où l'enquête visait à trouver des signes que l'approche culturelle ćtait significative pour les étudiants. Il semblait avoir des preuves pour seulement un degré limité de succès en termes d'étudiants qui mentionnaient véritablement ces genres d'idées. En analysant les résultats, pour atteindre un plus grand nombre étudiants nous proposons qu'il serait peutćtre nécessaire d'adresser directement les messages implicites et explicites concernant ce qui est important de savoir sur le développement humain. De plus, nous devrions peut-être aussi regarder les suppositions sous-jacentes au niveau du programme ainsi qu'au niveau des cours individuels. Les implications au niveau de l'enseignement sont présentées.
\end{abstract}

Correspondence should be addressed to:

Dr. Judith K. Bernhard, School of Early Childhood Education, Ryerson Polytechnic University,

350 Victoria St., Toronto, Ontario. MSB $2 K 3$

Email: jbernhar@acs.ryerson.ca 
Conventional courses in human development have been based on the paradigm of a decontextualized, generic child who progresses through universal stages on the way to maturity. This dominant perspective is echoed by most of the standard textbooks. However, an alternative perspective exists with substantial evidence to support it: specifically, that human development can be understood only within contexts of people in families, societies, and cultures (Barton, 1994; Bronfenbrenner, 1979; Bruner, 1990, 1996; Cole, 1990). This latter position is in accord with the recent draft statement of the National Association for the Education of Young Children regarding developmentally appropriate practice (NAEYC, 1995). Thus, the purpose of this paper is to examine how student teachers responded to the presentation of a cultural-contextual approach during a human development course.

To begin with the term culture, most definitions of the concept include the idea of shared meanings based on symbolic systems. For example, one traditional definition (Kroeber \& Kluckhohn, 1952) reads as follows:

... [culture includes] patterns, explicit and implicit. of behoviour, acquired and transmitted by symbols, constituting the distinctive achievement of human groups, including their embodiment in artifacts; the essential nature of culture consists of traditional ideas especially their attached values; culture systems may be considered as products of action, and as conditioning elements of further action. (p. 357)

Culture molds human potential in ways that are adaptive to particular environments, in part through the meanings socially assigned to life activities, life stages, and social roles. Different meanings are given to specific events across time and cultural milieu. Thus there is no generic child and, in semiotic terms, there are no generic signs of proper human development.

Although we have not surveyed all North American courses on child development, our teaching experience and examination of dozens of textbooks lead us to conclude that standard courses centred on such books are typically based on an eclectic use of a number of stage theories, with Piaget's holding a prominent place. Though some such books in recent editions have added cross-cultural examples and photo- graphs of children from non-North American countries, such revisions appear still to be adjustments to frameworks based on universal stages or 'milestones' regardless of how these transitions are styled. Our approach, by contrast, has stressed cultural context more than universal patterns. For example, we propose that a child's not talking at one year or not sitting at six months can be interpreted only within a specific cultural milieu.

Differences of interpretation were illustrated by Gonzalez-Mena (1997) as follows: She presented two contrasting patterns of parents putting a six-month old baby to sleep. In the first, the parents put the baby in a crib in a separate room while the parents slept at night. If Western students were asked, "What does it mean?" they would likely answer "nothing"; the normal course is not viewed as a sign of problems or difficulty. In the second pattern, the baby is put to sleep in the family bed in the midst of family activity. Western students are likely to interpret this action as a sign of over-attachment. In fact, if one were to describe these two alternatives to others around the world, in some cultures it might be suggested that the parents in the first pattern were cruel to isolate the baby so completely. According to our approach this sort of question is treated as having no universal 'right answer'. The question of what is normal or what can be expected of a child depends on meanings assigned to childhood and to child-parent joint activities within the cultural milieu.

Reflecting such an approach, DSM-IV, the newest version of the diagnostic manual of the American Psychiatric Association (1994) explicitly recognized that the evaluation of any alleged sign or symptom cannot be separated from considerations of what is common practice in an individual's culture (see p. 843).

The same is true of character traits that are valued and encouraged in children. In the 1920s and 1930s, on the other hand, universalists presented characteristics and milestones as universal markers of healthy child development of all human children. For example, it was a norm for two-year-olds to be somewhat willful and uncooperative. Our recent exposure to diverse cultural practices of immigrant groups has reminded us that taken-for-granted issues such as independence or willfulness in children and control of emotions are culturally determined (Bernhard, Lefebvre, Chud, \& Lange, 1995; Gonzalez-Mena, 1995). The actions 
of immigrant and refugee children in early childhood education centres are frequently misunderstood: When they cling to parents upon being left in the centre, the meanings assigned by the teachers often include immaturity, and the inference is of family dysfunction rather than an alternative interpretation, such as normal responses to trauma (Bernhard \& Freire, 1996).

The first author's experience more generally has been that teachers, graduates from courses based on universalist, "standard" models of human development, do not frequently interpret child behaviour within a cultural context. Universal standards and universal meanings are assumed. Differences from norms are generally interpreted as signs of deficiencies, disorders, or deviance (Bernhard, 1995; Cummins, 1996).

There has been some published evidence regarding communication problems between carcgivers and families around cultural issues (Bernhard, Lefebvre, Kilbride, Chud, \& Lange, in press; Chang, Muckeiroy, \& Pulido-Tobiassen, 1996). Holloway, Rambaud, Fuller, and Eggers-Pierola (1995) pointed out the effects of universalistic assumptions concerning what is most beneficial to young children. They explicitly call for a recognition of

... the implicit cultural views concerning authority and social relations expressed in prescriptive writings concerning 'appropriale' practices... There is much to be gained [they recommend] by seasoning professional knowledge about effective pedagogies with respectful consideration of parents' cultural models of child-rearing and education. (p. 470)

In response to the issue of appropriate practices in diverse contexts, a number of instructors have sought to teach prospective teachers about what culture is, and how the meanings assigned by a given culture affect judgments about children's health and normal development. We have found no published reports, however, about attempts to address cultural diversity within the basic conceptual framework proposed in early childhood education programs. We have seen one published report, by a social work professor, on teaching a multicultural approach (Arnold, 1995).

\section{Principles of the Cultural Heterogeneity Approach}

The focus of the cultural-contextual approach to human development is to recognize the fact that considerable differences exist among individuals, especially among those from diverse sociocultural backgrounds. These differences range from those commonly labeled biological (e.g., eating and sleeping patterns) to those recognized as social (e.g., language).

Several existing models are based upon substantial or thorough recognition of diversity. Bronfenbrenner's (1979) model elaborated an ecology of human development. The basic premise is that an ecological approach is

...the scientific study of the progressive, mutual accommodation between an active, growing human being and the changing properties of the immediate settings in which the developing person lives, as this process is affected by relations between these settings, and by the larger contexts in which the settings are embedded. (p. 21)

The first proposition states that ecological research is based on system concepts and focuses on processes that take place within and between persons and their environments. Bronfenbrenner criticized mainstream research for its "focus on characteristics of individuals almost to the exclusion of the properties of the social [and cultural] contexts in which the individuals are found" (p. 39). Some more recent frameworks in the field have been inspired by Bronfenbrenner's work, such as those of the life-span developmentalists, Baltes (1987) and Lerner (1988, 1991).

Rogoff(1990) represents a slightly different way of contextualizing development. Her empirical study of situated thinking (see also Lave \& Wenger, 1991) used many of the same concepts as Baltes and Lerner, but was derived primarily from Scribner (1985), Cole (1985), and Vygotsky (1987). Rogoff viewed development as having universal as well as local characteristics. For instance, in a community based on household food production, "children's development is not thought to be based on independent functioning but on their effective participation in tasks in which they have become proficient" (Rogoff, 1990, p. 56) so as 
to avoid wastage of materials. Since development is multidimensional, it does not follow a unidirectional course, and there is no one specific goal (Super \& Harkness, 1986).

Does the stress on difference and heterogeneity preclude the development of a unified theory of psychology? Not necessarily. Of course, a unitary theory assigns a subordinate role to differences. Supposing, however, that differences are foundational, a unitary theory must somehow embrace and explain that diversity. Alternatively, it may be possible to develop a variegated body of psychological knowledge without seeking unity: Koch (1985) explicitly called for a field of psychological studies rather than a single scheme of psychology. Such studies, based on investigation over the wide historical spectrum of human activity, would not aim at a single, universal truth about humans. Different theorists represent "different perceptual cuts on the same domain", hence the conclusions may not be strictly comparable; they imply "different universes of discourse" (Koch, 1985, p. 93; see also Schweder \& Sullivan, 1993).

In the last few years, the first author has attempted to revise her human development courses to reflect multifaceted and multidirectional phenomena embedded in cultural and historical contexts. Like others in the field, she has sought to teach about patterns of adaptation to particular environments (contexts) rather than about universal norms. Her approach has been through infusion, not through adding a unit of instruction proposing a cultural-contextual approach. The second author played a critical role in designing and conducting the evaluation of the effectiveness of such efforts.

Given a pluralistic society of diverse cultures and races and the reflection of such diversity among children, it appears necessary for all professionals in the field to gain the widest possible understanding of the differences and common threads among cultures, in particular, to appreciate nuances of meaning that cultures assign to children's patterns of behaviour (Derman-Sparks, 1989). The central question therefore was: Within the present institutional system of
Table 1

Characteristics of Students Enrolled in ECE Program

\begin{tabular}{crr}
\hline Gender $^{*}$ & & \\
Female & 78 & $96.3 \%$ \\
Male & 3 & $3.7 \%$ \\
Total & $\mathbf{8 1}$ & $\mathbf{1 0 0 . 0 \%}$
\end{tabular}

\begin{tabular}{lrr}
\hline Age ${ }^{*}$ & & \\
19 or younger & 47 & $58.0 \%$ \\
20 to 24 & 30 & $37.0 \%$ \\
40 to 44 & 1 & $1.2 \%$ \\
not stated & 3 & $3.7 \%$ \\
Total & $\mathbf{8 1}$ & $\mathbf{1 0 0 . 0 \%}$ \\
& & \\
\hline Mother Tongue ${ }^{* *}$ & & \\
English & 220 & $82.8 \%$ \\
Italian & 14 & $5.3 \%$ \\
Greek & 9 & $3.4 \%$ \\
Portuguese & 6 & $2.3 \%$ \\
Spanish & 2 & $0.8 \%$ \\
Chinese & 2 & $0.8 \%$ \\
Gernan & 2 & $0.8 \%$ \\
Pakistani & 2 & $0.8 \%$ \\
Polish & 1 & $0.4 \%$ \\
Not specified & 6 & $2.3 \%$ \\
Total & 264 & $\mathbf{1 0 0 . 0 \%}$
\end{tabular}

$\begin{array}{lrr}\text { Visible Minority 'Membership' * } & \\ \text { Member } & 29 & 11.0 \% \\ \text { Non Member } & 165 & 62.5 \% \\ \text { Not Stated } & 70 & 26.5 \% \\ \text { Total } & 264 & \mathbf{1 0 0 . 0 \%}\end{array}$

\begin{tabular}{lrr}
\hline Parents' Combined Income & * & \\
under $\$ 20,000$ & 12 & $4.5 \%$ \\
$20,000-29,999$ & 23 & $8.7 \%$ \\
$30,000-39,999$ & 26 & $9.8 \%$ \\
$40,000-49,999$ & 26 & $9.8 \%$ \\
$50,000-59,999$ & 36 & $13.6 \%$ \\
$60,000-74,999$ & 24 & $9.1 \%$ \\
$75,000-99,999$ & 32 & $12.1 \%$ \\
$100,000-149,999$ & 17 & $6.4 \%$ \\
150,000 or more & 10 & $3.8 \%$ \\
Not Stated & 58 & $22.0 \%$ \\
Total & $\mathbf{2 6 4}$ & $\mathbf{1 0 0 . 0 \%}$
\end{tabular}

* Source: University Planning Office Custom Tabulation, Registered students in first-year level of Early Childhood Education fulltime degree program on November 1, 1994.

** Source: Ryerson Polytechnic University (1992). 1991 Survey of students in full-time and part-time degree and diploma programs. University Planning Office. 
early childhood education, how can a cultural-contextual approach be effectively taught to students in a human development course?

\section{METHOD}

\section{Course Setting}

During the 1994-1995 academic year, we gathered a variety of data on the reactions of 81 students enrolled in a human development course taught by the first author. Students were in the first year of a four-year undergraduate program in early childhood education (ECE). The university is located in the center of one of the most ethnically diverse cities in the world. The demographic data for all the ECE students summarized in Table 1 below, however, shows the limited extent to which the diversity is reflected in this sample.

The data in Table 1 are derived from two sources: (a) a tabulation of students registered in the program, and (b) a university-wide survey two years earlier (Ryerson Polytechnic University, 1992). An inspection of Table 1 shows the following strong pattern: (a) ECE students were $96 \%$ female, (b) $58 \%$ of the students were aged 19 or younger, (c) $82 \%$ had English as a mother tongue, (d) the median family income was approximately $\$ 60,000$ per year, and (e) $10 \%$ of the students identified themselves as being of a visible minority.

The catalogue description of the course is given in Table 2, and the course objectives are listed in Table 3.

Among the objectives is the goal of helping students question assumptions of the universality of children's developmental patterns and in a practical sense, laying a foundation for properly interpreting children's behaviour in the centres in which students will be working. In order to teach objective number 2 , it was stressed throughout the course that assessments of "normal development" can only be made in terms of the meanings and signs of a child's own culture. This first-year ECE course ran for three hours per week and extended over two semesters for a total of 26 weeks. The meetings consisted primarily of lectures and class discussions.
Table 2

\section{Course Description and Objectives}

\section{Description}

This introductory course is considered a foundation to subsequent Early Childhood Education courses, providing a sound basis for the student's understanding of self and of children and their families. An analysis of current theories and contemporary research findings will form the core of the course.

Emphasis will be on continuities as well as qualitative stages of development and such development will be considered in terms of adaptation to the diverse environments in which human beings live. Family, community, culture, and society are the contexts which shape the norms of infancy, childhood, and adolescent development. Human functioning is best understood in terms of the mutual influence of biological, psychological, and social factors.

\section{Table 3 \\ Course Objectives}

1. To examine psychologists' and educators' constructions of the child and of the field/science of child and adolescent development. A varicty of theorists and constructs that help explain development will be considered.

2. To assess whether child and adolescent development can be correctly described by universal principles and stages and to determine the role of cultural context in patterns of growth and development.

3. To recognize the difficulties of obtaining sound, reliable, and unbiased evidence in the field. To illustrate methods of investigation which honour the perspectives and power of the participants.

4. To help students understand their personal and ethical development within their own ethnocultural and social context.

5. To begin to develop skills for contextual interpretation of child behaviour and fostering ethical responses to inequality and bias.

6. To begin to develop skills for critical analysis of the research literature and the popular media. 


\section{Reaction Papers}

Students completed six reaction papers throughout the year on particular topics or aspects of the course that sparked their interest (e.g., a portion of the textbook, an assigned reading, or lecture material). The six papers were ungraded but required in order to complete the course. The reaction paper forms included a variety of questions (see Appendix A). Reaction papers were identified by course section, student number, and reaction paper number and analyzed for themes in an iterative approach. Three raters reached agreement on themes addressed by students

\section{Informal Course Evaluations}

At the end of the course students were given a course-evaluation form with the following questions: What is the major thing you learned from this course? What topics should be added? What topics should be expanded upon? What topics should be deleted? Data from the final evaluations were sorted for themes

\section{Interviews}

Based on an analysis of the reaction papers, students who showed substantial consideration of theoretical frameworks in their papers were invited to an interview. After they had received their final grades, they were seen by an undergraduate research assistant. The eight students interviewed, essentially a voluntary sample, were assured that any identifying information would be removed during transcription of the interview. They were informed that the purpose of the interview was to help learn more of their thoughts beyond the words written in the reaction papers. Interviews were semi-structured, including questions such as "How should I interpret what this means?"or "Help me make sense of what you understood about this?" Interviews were taped, transcribed, and coded by emerging themes (Miles \& Huberman, 1994). Interview data were identified by case study number only.

All eight students interviewed were female and between the ages of 19 and 25 years. They identified themselves as Italian, Caribbean, Chinese, Latina, South Asian (2), and White (3). During the one-hour interview, students were asked to elaborate on the reaction papers they had written during the year.

\section{RESULTS}

\section{Reaction Papers}

Specific topics covered in the 505 reaction papers from the 81 students are reported in Appendix B. Most topics or items reported do not directly relate to issues of cultural context so they will not be discussed here. It is noted that the students apparently understood that the papers were to have a topical focus. Indeed, it is to be emphasized that cultural context was not addressed as one (e.g., weekly) topic among others. The focus of the present analysis is on the $7.7 \%$ of the reaction papers (representing 39 students) that mentioned theoretical frameworks or cultural context. The 39 students must be considered as a sample of convenience; we have no information as to their representativeness in the larger, course population. No students were directly asked about crosscultural issues so we cannot interpret absence of such mention in those who never referred to these issues.

Fifteen of the 39 students (hereafter designated simply by number) mentioned cross-cultural views directly and showed an understanding of cross-cultural issues. One example was the set of comments provided by student number 35 :

I am more aware that children react to situations according to their cultural experiences. I had a child in my group who was a new immigrant from Sri Lanka who cried and wouldn t leave the washroom leven though she was apparently finished], and I couldn't understand why... [then] I realized that the child would not leave the washroom because she was used to being washed after she used the toilet. I am aware of the need to be more sensitive to cultural issues which may not be readily apparent.

The puzzling sign, not leaving the washroom, was reinterpreted by this student in a contextualized fashion. She also elaborated on practical actions she would take to further her knowledge:

When in the field, I will ask questions in a respectful manner and talk to parents, show interest and be open to different ideas and concepts. 
Evidence of some (lesser) degree of understanding was shown by student number 20 as she reacted to a video of a grandmother massaging an infant for increased flexibility.

I have learned that one way is not necessarily the right way to bring up children, and different cultures believe different things.

One student (number 38 ) made an observation of her understanding of Freud's theory:

I am puzzled at why a famous developmental specialist didn't look at the fact that not all kids go through this. It is amazing how he could claim that all children experience this.

Some students began to react against a peer's unconsidered assumptions about what is normal. One Spanish-speaking student (number 20 ) commented on child abuse.

My only negative reaction is toward a comment made by one of the presenters. It had to do with the way some Chinese people cure headaches and fevers by nubbing a heated coin along a person's back. Her comment was "Well, we're in North America now so try and use Tylenol." Someone should point out to her that Tylenol isn t for everybody, and that if that [other] procedure works, well then it works.

A second student (number 13) commented on the issue of what is normal.

I was a little annoyed by some of the judgments made by the [peer] presenter. She used words like "normal" and "strange" to describe the family members, which I found slightly offensive.

There was some evidence that the theory of Piaget had a great hold on students. Although Piaget was discussed in the course, there was an effort not to employ his particular stage framework. However, many students found it useful to learn about Piagetian concepts:

Teachers have to know that children are in a certain stage so they will be able to teach child positively. This way they can plan their activi- ties according to the child's stage. (student number 1 )

I was quite intrigued with the issue that infants actively seek to assimilate their environmental experiences... and must adjust [accommodate] to the world. (student number 26)

I learned that l'iaget was a major contributor to the study of ECE; his many theories and concepts are highly respected. (student number 8 )

\section{Informal Course Evaluation}

Of the 25 students who returned the written course-evaluation forms, only seven referred to the role of culture in development. Most of the material is beyond the scope of this paper, but it is noted that in response to the question, "What topics should be added?", only three students wanted further information about other cultures and cultural aspects. In response to the question, "What topics should be deleted?" three students mentioned the cultural-oontextual perspective; no one mentioned developmental stage theories.

\section{Interview Data}

The interview data were collected to elaborate students' understanding of specific issues with a particular focus on theoretical frameworks. Students discussed their views of the practical applications of theory and their desire to hear more about certain topics. The transcribed interview data provided a basis for explaining how the student teachers had come to understand human development. The students are not necessarily representative of those in the larger course. The following themes emerged from the interview data; they are to be treated as suggestive, however, and should not be generalized to the larger ECE student population.

Nurturance/discipline. Students assigned various meanings to the discussions of nature-nurture issues. One student said this discussion had made her understand the need to consider the individuality of children and that not all children need the same things at the same time. On the environment side, the student recognized the important influence of parents on children. Essentially, her approach was to try to recog- 
nize what children come equipped with and then proceed to develop their abilities (student number 3).

Issues of discipline and behaviour guidance were mentioned several times.

[Theories] are helpful, but when I'm in placement, my main focus is I'm trying to build up that behavioural management. Piaget has really given me a better understanding of the child's development... [but] when it comes to practical [strategies], not a whole lot. (student number 5)

[If children] have a behavioural problem or whatever, maybe they could have learned it from home. (student number 8 )

Abuse indicators. Students elaborated on their views regarding child abuse. Some students said spanking children was normal and acceptable:

I think that sometimes, the kids need to feel the pain to know that they re doing something wrong... that 's how I'm brought up....And I still have my self confidence and I can't say it's a no-no kind of thing. (student number 3 )

She then proceeded to say one of the most useful things she had leamed was the official indicators of the abuse of children.

So I find it very important for us to know what they are and to know that at least we should be able to know how to tell the difference of really abused children or someone just trying to punish them thinking that it could help... those classes are very special for me and they stay in my mind and this is one topic that I learned most from in the course. (student number 3 )

This student did not, apparently, display awareness that cultural factors are relevant in assessing abuse. The meaning of parental behaviour demands different interpretations in different cultures because, for one thing, different intentions are attributed to the behaviour:

Child outcomes may [also] have different meanings. It does not make sense to equate bruises inflicted by an angry parent with [those of] a child who is bruised through the Vietnamese curing practice of cao gio (coin rubbing). (Korbin, 1993, p. 40)

Race. Students' understandings of race issues had several dimensions. One student commented on the role of teachers in the development of racial awareness:

The term 'race' isn't really that useful... [what is important is ] what the difference implies in their [children s] eyes. [Infants] start recognizing "difference' very soon. but then how they interpret it is what we should help in...those classes started me thinking about cultural difference and I became more and more aware of how this is happening. (student number 3 )

Universality issues. In spite of the emphasis on the need for culturally embedded interpretations of behaviour, students appeared to find the labels for stages most helpful in their practice with children.

I think you sort of apply to the child when they're at a certain stage... if you see a child and measure certain things you say, he's in the conservation stage or whatever...so you see the transition and apply the theory to the individual stages of the child...so then you know sort of like it's normal to act that way cause he $s$ in this stage. (student number 1 )

Student number 3 was frustrated with the culturallybased interpretations and said in her reaction paper: "I am quite confused because it seems like there is no definite answer and there will not be one."

Students seemed to retain their prior conceptions of what is appropriate child-rearing at particular ages. Student number 4 commented: "I was really shocked to hear that some mothers are still breast feeding their children when the child is five years old...it's not that it bothers me but it just seems a bit strange"

Stages were not seen as ruling out cultural issues. Student number 7 wrote about cultural tools and adults' roles in helping and guiding children. 
If you don't know where a child is "coming from" or what they do on a day-to-day basis, you have no idea about that child.... [We need to know about] culture and cultural tools... that what may be important to a child living in a particular environment may have nothing to do with the life of somebody else. [We should not] always give them everything [but] allow them to work through things themselves and challenge them a little bit and as you are challenging them, you will sort of pull them forward.

\section{Summary of Findings}

We have evidence for only a small degree of success in conveying the cultural-contextual approach; many other issues were more salient for these students. Apparently, the issue of culture stood out for only a limited number. As reported above, $7.7 \%$ of the reaction papers mentioned theoretical frameworks, and only 3 of 24 students wanted more information on cultural-contextual approaches. The $7.7 \%$ figure, however, is not easily interpreted since cultural diversity was infused throughout the course content. On specific issues, however, there were signs of a beginning of insight. Some of the students remarks on topics such as abuse and discipline apparently reflected a degree of appreciation of cultural differences. Overall, the salience of universal patterns and stage theories of Piaget and Erikson was high, despite the lectures' focus on non-stage theories.

\section{DISCUSSION}

The definition of culture by Kroeber and Kluckhohn (1952) that emphasized traditional ideas and attached values is entirely relevant to the present situation. The results of this investigation prompt two main queries: (a) Why was the cultural-contextual framework not evident in students' responses and evaluations of the course, and (b) How might these suggestive findings support the continued evolution of diversity-oriented courses in developmental psychology, in particular, those whose theoretical frameworks are cultural-contextual?

With respect to the first query, several plausible hypotheses might be suggested that could be confirmed in further research. First, students in the ECE program were trying to learn the signs that would help them to understand better the behaviour of developing human beings. In the process of achieving this goal, the students found themselves in a program that functioned as a particular sociocultural vehicle that guided and directed them to specific "worthy" signs of learning (e.g., Innis, 1985; Mertz \& Parmentier, 1985). And, in the program at large, these worthy signs included knowledge of Piaget's developmental stages. For example, Student 2 stated in her interview "all we hear is Piaget, Piaget!", and other students made reference to more detailed (therefore, "better") coverage of Piaget in other courses. In addition, the written texts and government documents pertaining to early childhood education in Ontario endorse the notion that knowledge of ages and stages constitutes the necessary information for understanding children.

Against this backdrop of both explicit and implicit messages, the first author's course in human development represented a distinct, minority approach involving the exposure of students to different views of standard signs (and to different sets of signs) that many students were not willing or able to integrate cognitively. To them, apparently, the formal signs that mattered involved universals in child development. Unfamiliar with the territory, they wanted sign posts in an easily understood, universal code.

A second hypothesis is that the cultural-contextual framework, as presented, appeared to be rather complex for the students. Findings from research on the differences between novices and experts may also provide some understanding of the present results (cf., Glaser \& Chi, 1988). Students in this human development course may be considered as novices in the area because they had no extensive formal experience in working with young children. Studies suggest that, when compared with expert performers in a given domain, novices possess, acquire, and use knowledge in very different ways (e.g., Berliner, 1986, 1988). Among these differences is the tendency for novices first to seek out deductive forms of knowledge that may be derived from specific rules or principles. This contrasts with the expert's ability to use what Peirce called 'abduction', that is, to create hypotheses that explain observed facts (Hartshorne \& Weiss, 1931; Smith, 1988). In the present context, students sought specific, proper indicators of common norms of development which the stage theorists such as Piaget, Erikson, and Kohlberg appeared to offer them, but which the cultural-contextual perspective did not. 
A third hypothesis is that the students' own cultural background as white, mainly Anglo- middleclass women may have contributed to the particular limitations of viewpoints. Given the relative lack of diversity in students' cultural backgrounds, it is plausible that course material may not be interpreted as intended. There is some research evidence indicating that simply having contact with different groups is not sufficient to reduce prejudice (e.g., Ahlquist, 1991; Zeichner \& Hoeft, forthcoming). This line of reasoning might be applied to the present course. The exposure to material, even persons, representing different practices may seem intriguing and exotic, but not as undermining the standards of normality. Because of such considerations, we agree with requirements, like those of the State of Wisconsin, for actual contact with parents and children of diverse backgrounds. Further, such contacts might be appropriate prerequisites for entry into ECE programs.

The second query arising from this study was: How might these suggestive findings support the continued evolution of diversity-oriented courses in developmental psychology, in particular those based on cultural-contextual theories? During the past two decades, research in Vygotskian and related traditions has shown the power and value of these perspectives for understanding human development (e.g., Moll, 1990; Smith, 1995). Further, the recently revised position statement of the National Association for the Education of Young Children (1995) recognizes the fundamental role of culture in developmental processes. Given this rapidly growing literature, educators would do well to adopt courses and programs that address recent advances in the field. The findings from this study indicate that a minority of students were able to incorporate a cultural-contextual perspective in understanding human development. That minority constitutes an important beginning in satisfying the goals of the course and of ECE program reform.

\section{Limitations}

The exploratory study presented in this paper was intended to raise questions for further investigation. The authors have each been active in teacher education for more than 15 years, but their intuitions regarding validity may properly be seen as awaiting objective validation. The question of proof of hy- potheses, in this case, specific effects in students, remains subject to further investigation with more rigorous methods, especially based on random sampling. Our results do not license generalization to larger populations of ECE students. The present findings are presented only as indicators of possible areas of difficulty in implementing planned changes.

\section{Implications for Teaching}

The following tentative suggestions are offered to ourselves and other instructors intending to encourage appreciation of cultural context within an explicit framework.

(1) Since you may be perceived by students as going against the grain, you would do well to help students become aware of the initial, perhaps unconscious, assumptions about human universality.

(2) To reach a larger number of students, it may be necessary to question in a deliberate way the explicit and implicit messages concerning what is important to know about human development. Hence, Piagetian and Vygotskian perspectives, for example, might be compared directly on particular issues affecting child development.

(3) Cultural heterogeneity can be addressed directly on specific topics such as discipline or teen pregnancy. Several views might be presented on what is considered normal and what is considered abnormal under varying sociocultural conditions. In this way, we link several sets of signs (that includes all associated symbols) with topics instead of endorsing, either explicitly or implicitly, the single sign-set that represents the dominant values and norms (see for example, Chud \& Falhman, 1996; diversity film video series, Gonzalez-Mena, 1996).

(4) Although the choice of textbook and lecture material is crucial, it is important as you adjust your expectations to consider the extent to which students are exposed to overall conventional, culture-blind material before the course, in other courses, and during their practicum experiences. 
(5) It is perhaps best to be modest in setting objectives regarding a change in mindset that can result from a specific course.

(6) You would do well to persevere in the face of a specific, course-related difficulty. But also involve yourself in wide-ranging collegial attempts to make appropriate program and curriculum revisions so that the study of human development better reflects Canada's diverse reality of nations, races, and cultures.

\section{Appendix A}

\section{Questions Addressed in Reaction Papers}

1. What is the topic you are reacting to?

2. Why is this topic of particular interest to you?

3. What have you learned from this? If you could state what you learned in one sentence, what would it bc?

4. Describe some of your positive reactions to this issue (e.g., excited, intrigued, captivated).

5. Describe some of your negative reactions to this issuc (c.g.. puzzled, angry, offended).

6. What could be done (and by whom) to improve this area?

7. What action will you take to further your knowledge in this area?

\section{Appendix B}

\section{Topics and Frequencies in Student Reaction Papers}

\begin{tabular}{lcr}
\hline Topic & \multicolumn{2}{c}{ Frequency } \\
\hline Sudden Infant Death Syndrome & 52 & $(10.3 \%)$ \\
Course organization & 52 & $(10.3 \%)$ \\
Childbirth methods & 51 & $(10.1 \%)$ \\
Nature and nurture & 49 & $(9.7 \%)$ \\
Homosexuality & 41 & $(8.1 \%)$ \\
Theoretical frameworks & 39 & $(7.7 \%)$
\end{tabular}

Culture, race 36

Child and sexual abuse $\quad 35$

$(7.1 \%)$

Eating disorders 30

Unique topics 29

Sexuality and gender $\quad 27$

language learning $\quad 17$

Teenage pregnancy $\quad 12 \quad(2.4 \%)$

Special needs $\quad 10 \quad(2.0 \%)$

Research methods $\quad 7 \quad(1.4 \%)$

$\begin{array}{lll}\text { Drug abuse } & 6 & (1.2 \%)\end{array}$

Breast feeding $\quad 6 \quad(1.2 \%)$

History $3 \quad(0.6 \%)$

$\begin{array}{lll}\text { Play } & 3 & (0.6 \%)\end{array}$

$\begin{array}{lll}\text { Total } & 505 \quad(100.0 \%)\end{array}$

The authors would like to thank: Suparna, Hal, anonymous reviewers, school of ECE, Janet GM.

\section{REFERENCES}

Ahlquist, R. (1991). Position, power and imposition: Power relations in a multicultural foundations class. Journal of Negro Education, 60(2), 158-169.

American Psychiatric Association (1994). Diagnostic and statistical manual of mental disorders. (4th ed.); DSM-IV. Washington, DC: Author.

Arnold, F. W. (1995). Developing and teaching a cultural pluralism course in one of America's "uneasy salad bowls": Immigration and ethnicity in Los Angeles. Teaching Sociology, 23, 94-110.

Baltes, P. B. (1987). Theoretical propositions of life-span developmental psychology: On the dynamics between growth and decline. Developmental Psychology. 23, 611-626.

Barton, S. (1994). Chaos, self-organization, and psychology. American Psychologist, 49, 5-14.

Berliner, D. (1986). In pursuit of the expert pedagogue. Educational Researcher, 15(7), 5-13.

Berliner, D. (1988). The development of expertise in pedagogv. New Orleans, LA: American Association of Colleges for Teacher Education.

Bernhard, J. K. (1995). Child development, cultural diversity, and the professional training of early childhood educators. Canadian Journal of Education, 20, 415 436.

Bernhard, J. K., \& Freire, M. (1996). Latino refugee children in childcare. Canadian Journal of Research in Early Childhood Education, 5(1), 59-71.

Bernhard, J. K., Lefebvre, M. L., Chud, G., \& Lange, R. (1995). Paths to equity. Toronto: York Lanes Press. 
Bernhard, J. K., Lefebvre, M. L., Kilbride, K. M., Chud, G., \& Lange, R. (In press). Troubled relationships in early childhood education. Early Education and Development.

Bronfenbrenner, U. (1979). The ecology of human development: Experiments by nature and design. Cambridge. MA: Harvard University Press.

Bruner, J. (1990). Acts of meaning. Cambridge, MA: Harvard University Press.

Bruner, J. (1996). The culture of education. Cambridge, MA: Harvard University Press.

Chang, H., Muckelroy, A., \& Pulido-Tobiassen, D. (1996). Looking in, looking out: Redefining child care and early education in a diverse societv. San Francisco: California Tomorrow.

Chud. G., \& Falhman, R. (1996). Honouring diversity within child care and early education: An instructor's guide. Burnaby, BC: Open Learning Agency.

Cole, M. (1990). Cultural psychology: A once and future discipline? In J. J. Berman (Ed.), Nebraska symposium on motivation: Cross-cultural perspectives ( $\mathrm{pp}$. 270-335). Lincoln, NB: University of Nebraska Press.

Cole, M. (1985). The zone of proximal development: Where culture and cognition create each other. In J. V. Wentsch (Ed.), Culture, communication, and cognition: Lygotskian perspectives (pp. 146-161). Cambridge, MA: Cambridge University Press.

Cummins, J. (1996). Negotiating identities: Education for empowerment in a diverse society. Los Angeles: California Association for Bilingual Education.

Derman-Sparks. L., \& the ABC Task Force (1989). Anti-bias curriculum: Tools for empowering voung children. Washington, DC: National Association for the Education of Young Children.

Glaser, R., \& Chi, M. T. H. (1988). Overview. In M. T. H. Chi, R. Glaser, \& M. J. Farr (Eds.), The nature of expertise (pp. xT-xxviii). Hillsdale, $\mathrm{NJ}$ : Erlbaum.

Gonzalez-Mena, J. (1997). Multicultural issues in child care. Mountain View, CA: Mayfield.

Gonzalez-Mena, J (1996). Early Childhood Training Series: Diversity. Magna Production.

Gonzalez-Mena, J. (1995, October). We are all one-the unitive dimension of being: Implications for child rearing. Paper presented at the Reconceptualizing ECE Conference, Santa Rosa, CA.

Hartshorne. C. \& Weiss, P. (Eds.) (1931). Collected papers of Charles Sanders Peirce (Vols. 1-6). Cambridge. MA: Harvard University Press.

Holloway, S. D., Rambaud, M. F., Fuller, B., \& Eggers-Pierola, C. (1995). What is "appropriate practice" at home and in child care? Low-income mothers' views on preparing their children for school. Early Childhood Education Quarterly, 10, 451-473.

Innis, R. E. (Ed.) (1985). Semiotics: An introductory anthology. Bloomington, IN: Indiana University Press.
Koch, S. (1985). The nature and limits of psychological knowledge: Lessons of a century qua "science". In S. Koch \& D. E. Leary (Eds.), A century of psychology as science (pp. 75-97). New York: McGraw-Hill.

Korbin, J. E. (1993). Child maltreatment and the study of refugee children. In F. Ahearn \& J. Athey (Eds), Refugee children. Baltimore, MD: John Hopkins University Press.

Kroeber, A. L., \& Kluckhohn, C. (1952). Culture: A critical review of concepts and definitions. New York: Random House.

Lave, J., \& Wenger, E. (1991). Situated learning: Legitimate peripheral participation. New York: Cambridge University Press.

Lerner, R. M. (1988). Personality development: A life-span perspective. In E. M. Hetherington. R. M. Lemer, \& M. Perlmutter (Eds.), Child development in life-span perspective (pp. 21-6). Hillsdale, NJ: Erlbaum.

Lerner, R. M. (1991). Changing organism-context relations as the basic process of development: $A$ developmental contextual perspective. Developmental Psychology, 27, 27-32.

Mertz, E., \& Parmentier, R. J. (Eds.) (1985). Semiotic mediation: Sociocultural and psychological perspectives. Orlando, FL: Academic Press.

Miles, M. B., \& Huberman, A. M. (1994). Qualirative data analysis: A new sourcebook of methods. Berkeley: Sage.

Moll, L. (Ed.) (1990). Lygotsky and education. New York: Cambridge University Press.

National Association for the Education of Young Children (1995). Responding to linguistic and cultural diversity: Recommendations for effective early childhood education. Young Children, 51(2), 4-16.

Rogoff, B. (1990). Apprenticeship in thinking: Cognitive development in social context. New York: Oxford University Press.

Ryerson Polytechnic University (1992). 1991 Survey of students in full-time and part-time degree and diploma programs. University Planning Office.

Scribner, S. (1985). Vygotsky's uses of history. In J. V. Wertsch (Ed.). Culture, communication, and cognition: Ligotskian perspectives (pp. 119-145). Cambridge: Cambridge University Press.

Shweder, R. A., \& Sullivan, M. A. (1993). Cultural psychology: Who needs it? Annual Review of Psychology, +4, 497-523.

Smith, H. A. (1988). Abduction and the signs of expertise. Paper presented at the meeting of the American Educational Research Association, New Orleans.

Smith, H. A. (1995). Cultural psychology and semiotics: Confronting meaning in educational practice. Canadian Journal of Education, 20, 407-414.

Super, C. M., \& Harkness, S. (1986). The developmental niche: A conceptualization at the interface of child and culture. International Journal of Behovioral Development, 9, 545-569. 
Vygotsky, L. S. (1987). Thinking and speech. In R. W. Rieber \& A. S. Carton (Eds.), The collected works of L. S. Vygotsky. (N. Minick, Trans.) New York: Plenum Press.

Zcichner, K.M., \& Hoeft, K. (in press). Teacher socialization for cultural diversity. In J. Sikula, T. Buttery, and E. Guyton (Eds.), Handbook of research on teacher education. New York: MacMillan. $\mathrm{n}$ 